\title{
Sistem Informasi E-Commerce Furniture Berbasis Web Pada Toko Mebel Ubaidillah Kamal Jepara
}

\author{
Muchammad Tirozul Achyar ${ }^{1}$, Fandy Indra Pratama ${ }^{2}$ \\ ${ }^{1,2}$ Mahasiswa Jurusan Teknik Informatika, Fakultas Teknik, Universitas Wahid \\ Hasyim J1. Menoreh Tengah X/22, Sampangan, Semarang 50236. \\ E-mail : achyar014@gmail.com
}

\begin{abstract}
Abstrak
Pesatnya perkembangan teknologi internet tidak ada batasan lagi orang untuk membantu atau mengambil informasi dengan cepat. Teknologi informasi akan mendominasi seluruh kegiatan yang ada karena pengguna internet menjurus kepada cyberspace yang memberikan kemajuan di segala bidang terutama pada bidang ecommerce yang menyababkan sistem penjualan dari konvensional menjadi digital. Toko Mebel Ubaidillah Kamal Jepara merupakan sebuah usaha yang bergerak di bidang furniture. Sistem penjualan dan promosi masih menggunakan sistem konvensional. Dari kendala tersebut membutuhkan sebuah sistem informasi penjualan untuk mengelola.. Dalam penelitian ini menggunakan Metode Waterfall dan Penelitian yang dilakukan menghasilkan sistem informasi e-commerce furniture berbasis web pada toko mebel Ubaidillah Kamal Jepara untuk memudahkan pembeli dalam melakukan pemesanan.
\end{abstract}

Kata kunci: Cyberspace, E-commerce, Metode Waterfall, Hasil

\section{PENDAHULUAN}

\subsection{Latar belakang masalah}

Pesatnya Perkembangan pada teknologi internet tidak ada batasan lagi orang untuk membantu atau mengambil informasi secara cepat. Dengan mengakses internet dapat mempermudah seseorang untuk menyelesaikan tujuannya untuk menunjang kegiatannya untuk mencari informasi, chatting, dan bermain game. (Pratama, dkk, 2020). Teknologi informasi akan mendominasi seluruh kegiatan yang ada karena pengguna internet banyak menjurus kepada cyberspace sehingga memberikan kemajuan di segala bidang terutama pada bidang $e$ commerce yang menyababkan sistem penjualan dari konvensional menjadi digital hal ini memberikan banyak keuntungan bagi produsen maupun konsumen yang bergelut di bidang penjualan. E-commerce pada akhir-akhir ini sudah marak dengan munculnya jutaan perusahaan yang menawarkan barang penjualan didalam website dan sosial media, contohnya Lazada, Buka Lapak, dan sebagainya (Irawan D., dkk, 2017)

Toko Mebel Ubaidillah Kamal Jepara merupakan sebuah usaha yang bergerak di bidang furniture seperti kursi tamu, meja rias, lemari, dan lain-lain. Sistem penjualan dan promosi masih menggunakan sistem konvensional dan masih menggunakan media sosial yaitu facebook dan lain sebagainya. Kesulitan customer untuk mencari informasi produk adalah sebuah kendala yang sedang dihadapi, karena untuk melihat informasi produk customer harus ke toko atau tempat produksi untuk mengetahui informasi secara terperinci. Kendala seperti ini yang akan berdampak pada berkurangnya niat customer untuk melakukan suatu transaksi pada customer yang tidak mendapatkan informasi.

Berdasarkan kondisi tersebut dibutuhkan sebuah sistem informasi $e$-commerce berbasis web untuk memudahkan pembeli dalam melakukan pemesanan. Dengan adanya sistem ini diharapkan dengan dapat meningkatkan angka penjualan dan layanan terhadap customer sehingga jumlah customer menjadi semakin meningkat serta dapat menghasilkan laporan penjualan secara teratur dan tersusun rapi.

\subsection{Rumusan Masalah}

Berdasarkan uraian latar belakang dan rumusan masalah yang sudah dijelaskan sebelumnya maka penelitian ini memiliki batasan-batasan yang mencakup :

a. Sistem mengelola produk furniture. 
b. Sistem mengelola profil toko, catalog produk, data pembeli, dan transaksi penjualan.

c. Sistem menghasilkan laporan penjualan yang teratur dan rapi.

d. Sistem hanya diuji menggunakan metode black box.

\subsection{Tujuan Penelitian}

Tujuan yang ingin dicapai pada penelitian sistem informasi e-commerce furniture berbasis web ini yaitu :

a. Menghasikan sistem informasi $e$ commerce yang memudahkan penjualan sehingga konsumen yang jauh tetap dapat bisa membeli produk tanpa harus datang ke toko atau tempat produksi.

b. Menghasikan sistem informasi $e$ commerce furniture berbasis web yang dapat menghasilkan laporan penjualan secara teratur dan rapi.

\subsection{Manfaat}

Manfaat yang diperoleh dari penelitian sistem informasi e-commerce furniture berbasis web ini yaitu :

a. Bagi Penulis

Penulis dapat menerapkan ilmu pengetahuan yang diperoleh dari Universitas Wahid Hasyim Semarang sebagai pengabdian ilmu ke dalam lingkup masyarakat. Menerapkan ilmu IT yang didapat untuk membuat sebuah sistem informasi yang berguna dalam bisnis.

b. Bagi Pembaca

Sebagai referensi atau acuan dalam menambah ilmu pengetahuan tentang $E$ commerce yang berbasis website.

c. Bagi Masyarakat

Sebagai referensi atau acuan untuk mencari dan membeli furniture yang disediakan Toko Mebel Ubaidillah Kamal Jepara Berbasis Website

\section{TINJAUAN PUSTAKA}

Menurut Penelitian sejenis pernah dilakukan oleh Kristanto dkk (2017) mengenai Penerapan E-Commerce Untuk Penjualan Furniture Pada UD. Tunggal Saudara. Penelitiannya menjelaskan tujuan pembuatan sistem tersebut adalah merancang sebuah aplikasi yang mampu memberikan informasi seputar produk- produk yang ditawarkan oleh
UD. Tunggal Saudara serta memberikan kemudahan dalam pengelolaan produk dan transaksi. Suatu implementasi teknologi dalam meningkatkan penjualan barang adalah menggunakan e-commerce untuk membantu memasarkan berbagai macam produk.

Penelitian sejenis lainnya juga pernah dilakukan oleh Indriyanto dkk (2020) mengenai Sistem Informasi Penjualan Meubel CV. Mandiri Furniture Berbasis Java. Penelitiannya menjelaskan tujuan sistem tersebut adalah untuk mempermudah dalam mengelola laporan barang dan keuangan serta memudahkan suatu proses transaksi pada costumer agar toko semakin maju. Karena laporan di toko masih menggunakan buku untuk media pencatatan pengelolaan laporan toko kurang efektif dan efisien, yang di khawatirkan adalah ketika catatan hilang akan mengganggu kearsipan pada toko tersebut akan mempengaruhi Pemantauan dan perkembangan toko, sehingga toko memperlukan suatu sistem administrasi untuk mempermudah kerja dari pengelola toko

\subsection{Landasan Teori}

\subsubsection{Sistem Informasi}

Sistem informasi merupakan sebuah komponen-komponen yang saling berkaitan dan untuk mengumpulkan, mengeluarkan, memproses, menyimpan, mendistribusikan suatu informasi untuk mendukung pengambilan keputusan dan pengambilan pengawasan dalam organisasi. (Kristanto dkk, 2017).

\subsubsection{E-Commerce}

Electronik Commerce dikenal juga dengan sebutan E-commerce merupakan suatu proses transaksi jual beli antara penjual dengan pembeli untuk menyediakan barang dan jasa atau mengambilan hak yang terjadi menggunakan bantuan dengan media elektronik yang hadir secara fisik. Medium ini muncul di dalam sebuah jaringan dengan menggunakan sistem terbuka yaitu dengan menggunakan. Transaksi ini akan terjadi terlepas dari batas suatu wilayah dan syarat nasional E-Commerce yang mempunyai dampak bagi proses jual beli. (Triharjono, 2012).

\section{METODE PENELITIAN}

Dalam penelitian ini metode yang digunakan dalam pengembangan sistem 
Vol. 3, No. 2, September 2021, Hal. 156-161

informasi yaitu metode waterfall. Waterfall merupakan metode yang menggunakan pendekatan sebuah sistem, setiap tahapan sistem akan dikerjakan dengan secara menurun dari requirement analysis and definition, system and software design, implementation, system testing, maintenance.

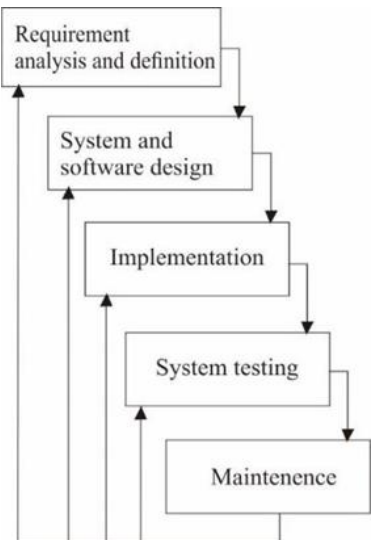

\section{Gambar 1. Metode Waterfall}

\section{HASIL DAN PEMBAHASAN}

Use case diagram yaitu sebuah pemodelan untuk perilaku (behavior) information system yang akan dibuat. Use case digunakan untuk mengetahui suatu fungsi apa saja yang berada di dalam information system dan untuk siapa saja yang berhak menggunakan dari fungsi- fungsi tersebut. (Hendini, 2016) Secara umum use case digunakan untuk mendeskripsikan fungsi apa saja yang ada pada sebuah sistem

\subsection{Use Case Diagram Admin}

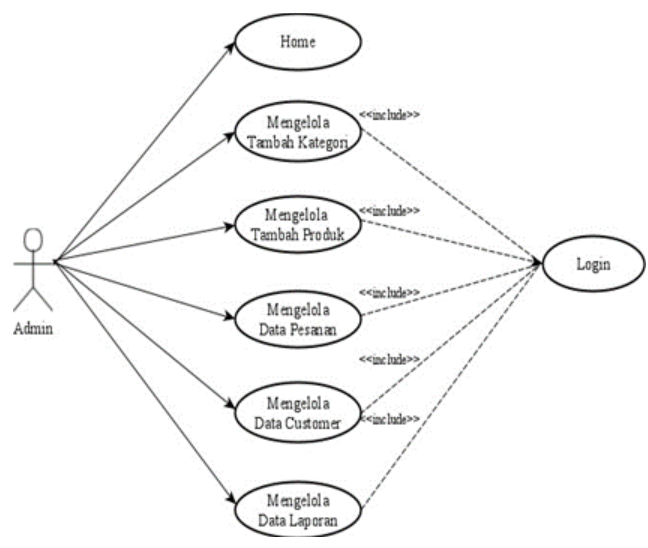

Gambar 2. Use Case Diagram Admin

\subsection{Use Case Diagram Customer}

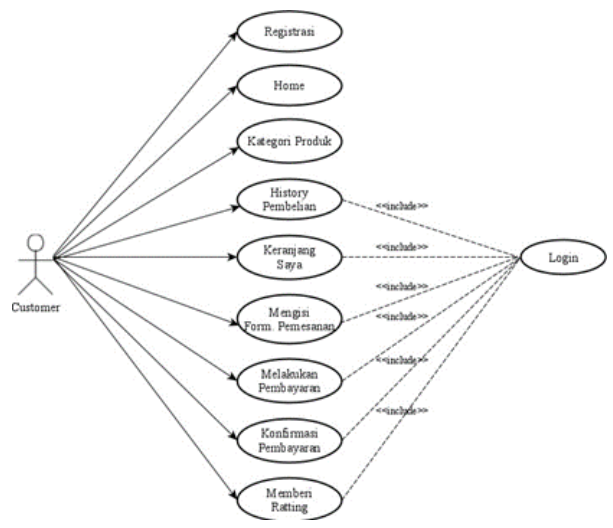

Gambar 3. Use Case Diagram Customer

Hasil dari apa yang telah dibuat sebelumnya disini adalah berupa sebuah sistem yang mampu membantu customer melakukan pembelian barang dan membantu Admin untuk mengelola data dengan mudah dapat dilihat sebagai berikut:

1. Halaman Login
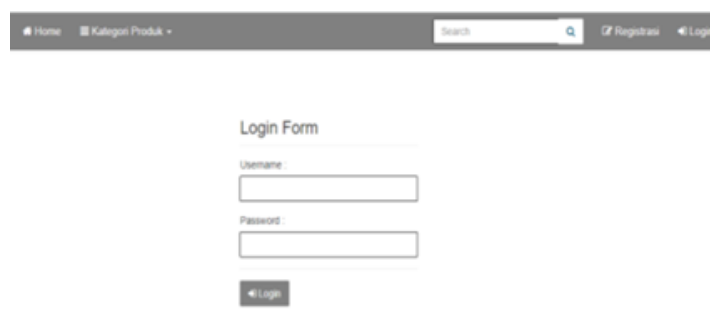

Gambar 4. Halaman Login

2. Halaman Registrasi Customer

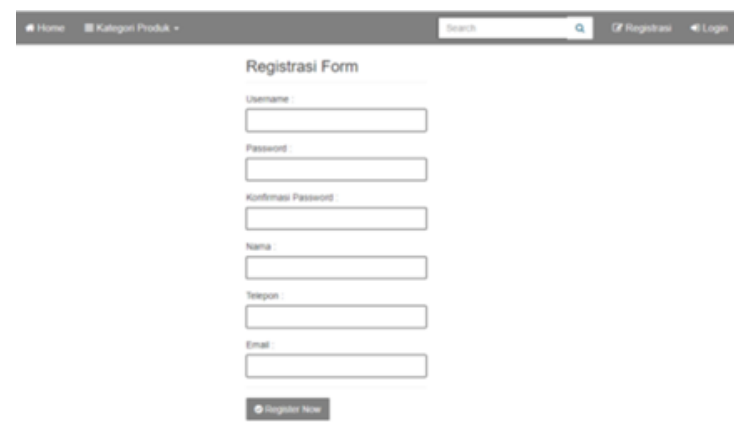

Gambar 5. Halaman Registrasi Customer 
3. Halaman Home

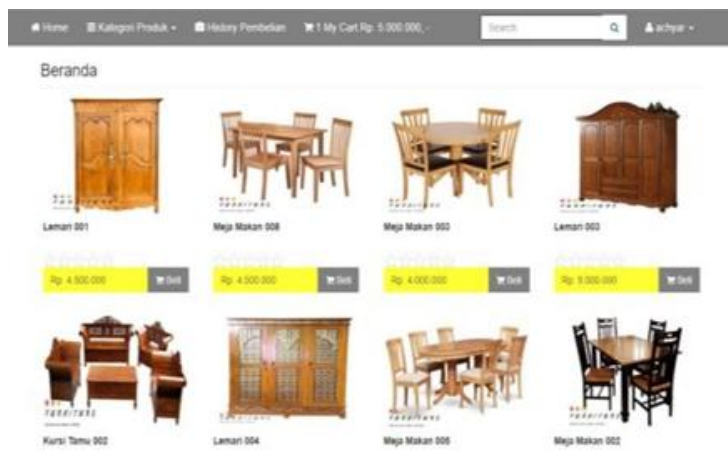

Gambar 6. Halaman Home

4. Halaman Detail Produk

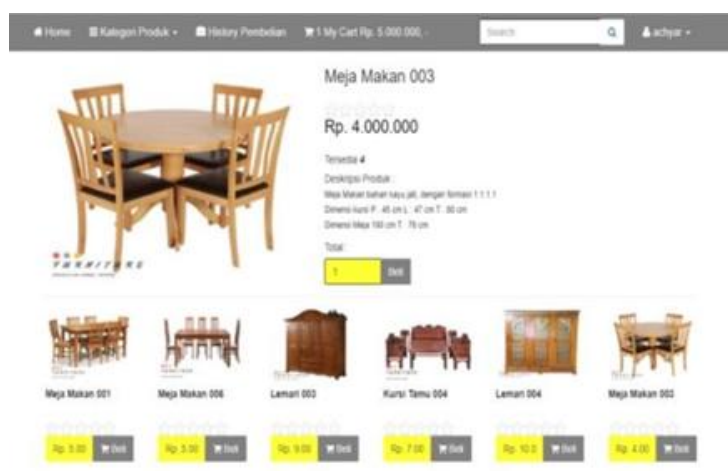

Gambar 7. Halaman Detail Produk

5. Halaman Keranjang Saya

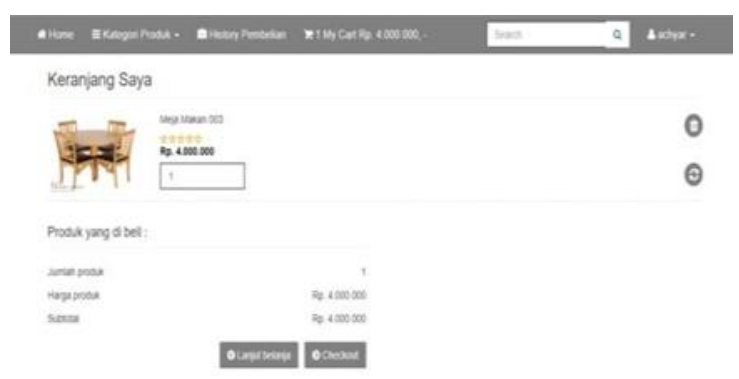

Gambar 8. Halaman Keranjang Saya
6. Halaman Checkout

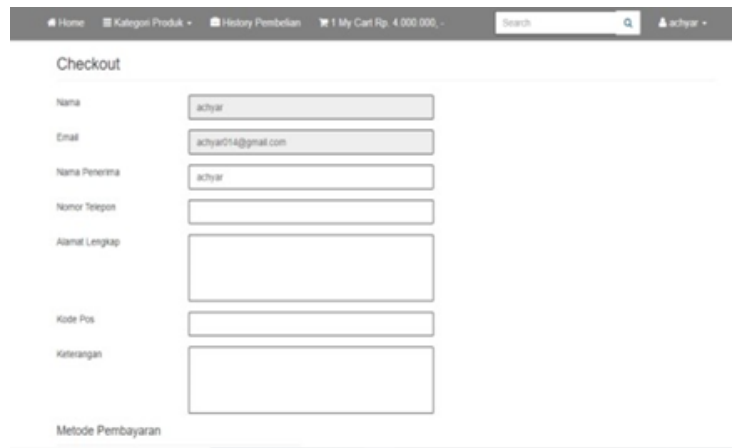

Gambar 9. Halaman Checkout

7. Halaman Konfirmasi Pembelian

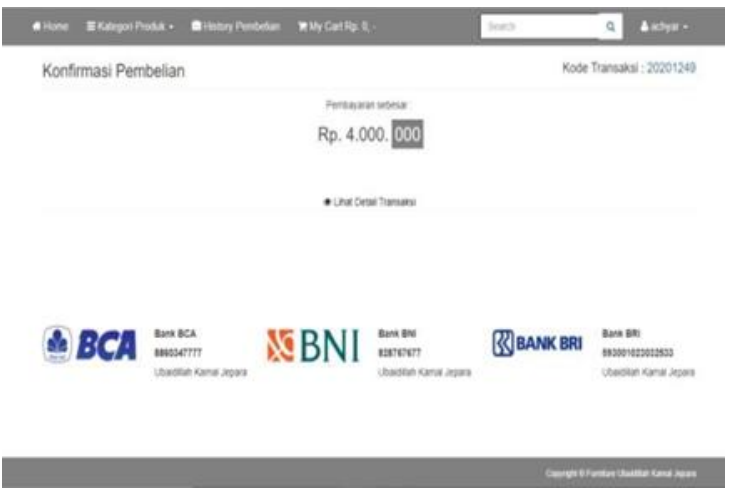

Gambar 10. Halaman Konfirmasi Pembelian

8. Halaman Detail Transaksi

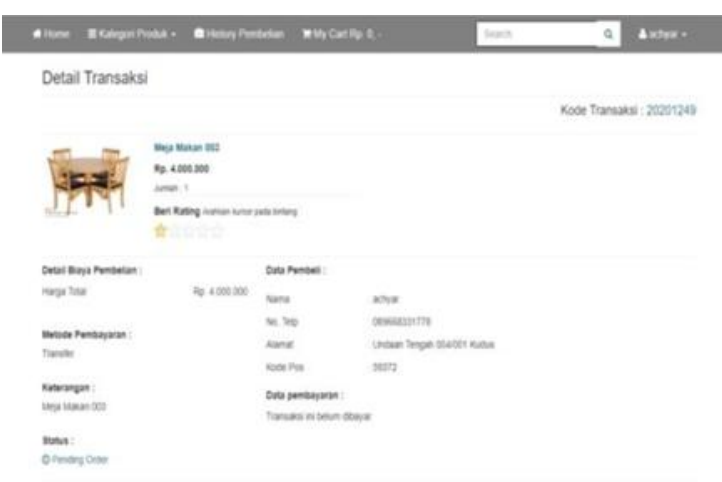

Gambar 11. Halaman Detail Transaksi 

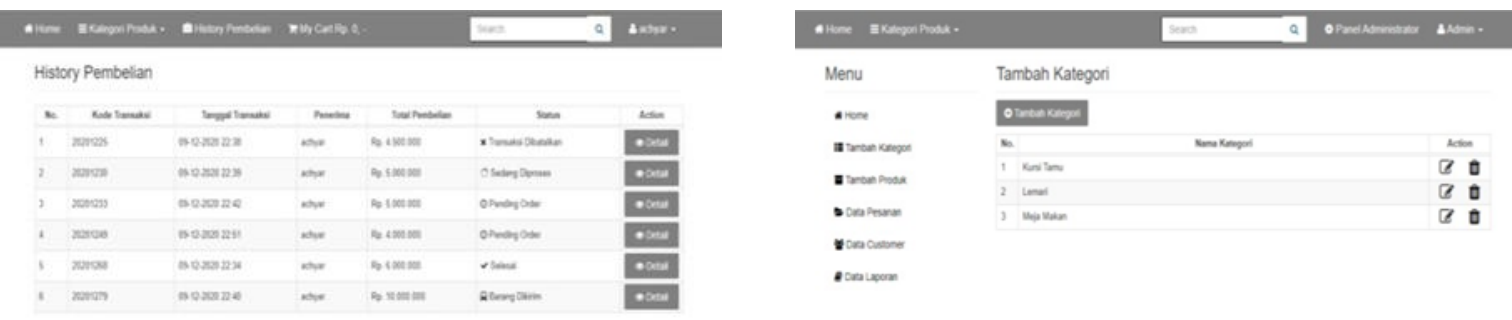

\section{Gambar 12. Halaman History Pembelian}

10.Halaman Admin Panel

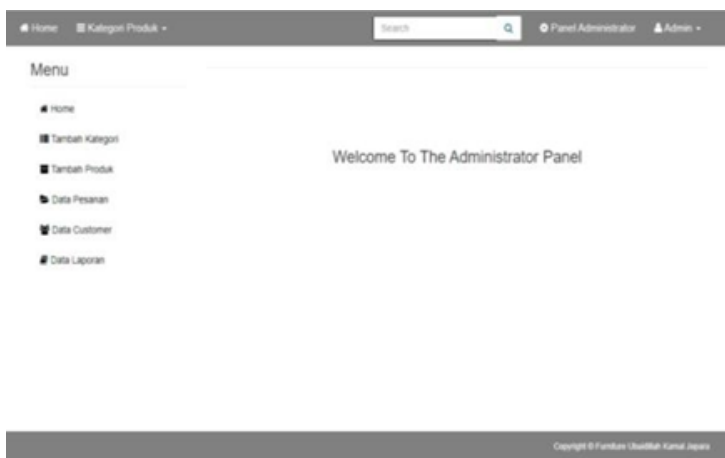

Gambar 13. Halaman Admin Panel

11.Halaman Home Admin

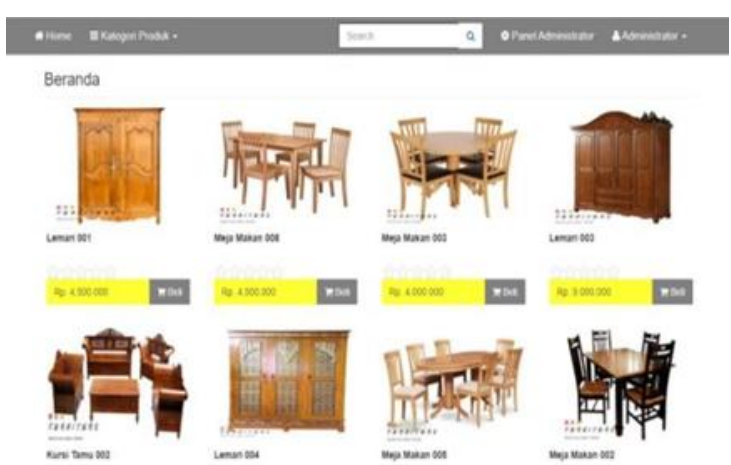

Gambar 14. Halaman Home Admin
Gambar 15. Halaman Tambah Kategori

13.Halaman Tambah Produk

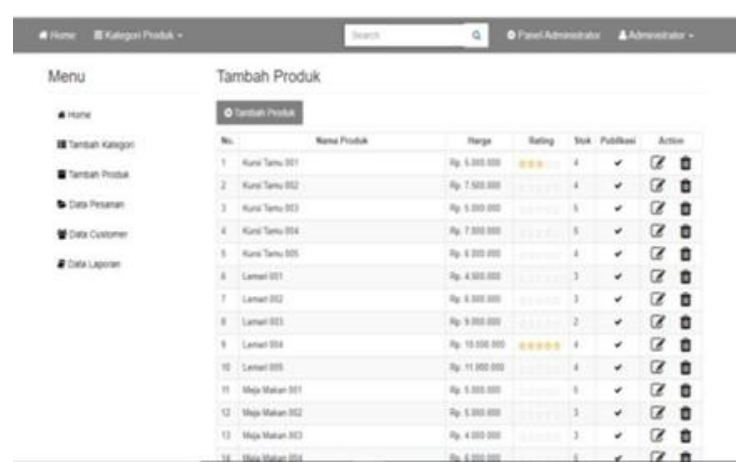

Gambar 16. Halaman Tambah Produk

14.Halaman Data Pesanan

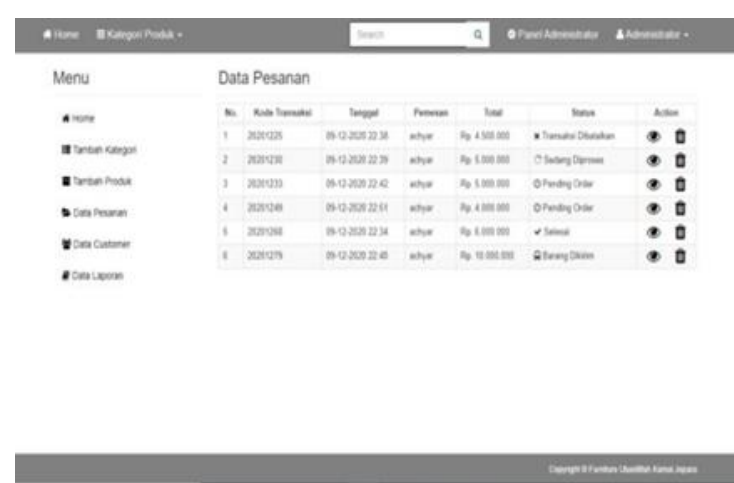

Gambar 17. Halaman Data Pesanan 
15.Halaman Verifikasi Data Pesanan

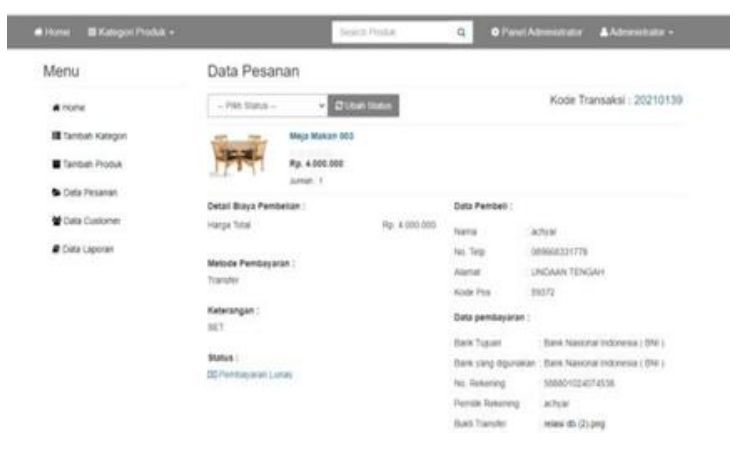

Gambar 18. Halaman Verifikasi Data Pesanan

16.Halaman Data Customer

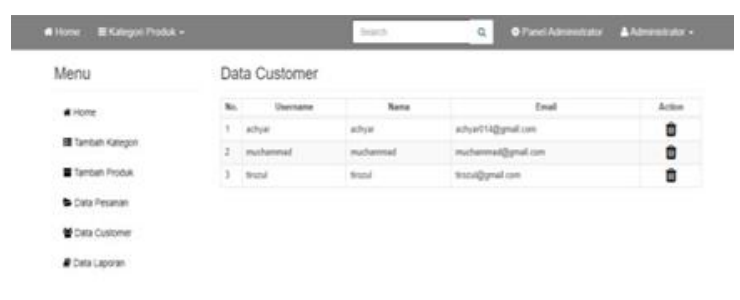

Gambar 19. Halaman Data Customer

17.Halaman Data Laporan

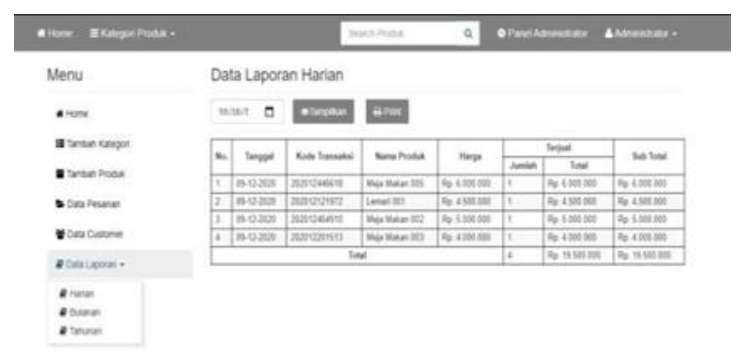

Gambar 20. Halaman Data Laporan

\section{KESIMPULAN DAN SARAN}

\subsection{Kesimpulan}

1. Sistem informasi penjualan berbasis web atau e-commerce dapat memeberikan kemudahan kepada customer untuk melakukan pembelian produk tanpa harus datang ke toko atau tempat produksi.
2. Sistem memberikan kemudahan kepada penjual dalam mengelola data produk, data pemesanan dan data laporan

\subsection{Saran}

a. Penulis berharap pada pengembangan selanjuatnya bisa menambahkan sistem chat untuk memberikan kemudahan kepada costumer ataupun penjual agar bisa berkomunikasi dengan baik.

b. Penulis berharap pada pengembangan selanjutnya bisa menambahkan sistem tracking untuk memberikan kemudahan kepada customer dalam memantau pengiriman produknya.

\section{DAFTAR PUSTAKA}

Hendini, A. (2016). "Pemodelan UML Sistem Informasi Monitoring Penjualan dan Stok Barang (Studi Kasus: Distro Zhezha Pontianak)". Jurnal Khatulistiwa Informatika, Politeknik Harapan Bersama, Pontianak. Volume 04 Nomor 2, 108-110

Indriyanto W., Abadi L.P., Kuncoro A. (2020). "Sistem Informasi Penjualan Meubel CV. Mandiri Furniture Berbasis Java". JRAMI. Volume 1 Nomor 2. Jakarta Timur.

Irawan D., Junaidi M., Rahsel Y., dan Udin T. (2017). "Perancangan Electronic Commerce Berbasis B2C Pada Toko Atk Sindoro". Jurnal TAM (Technology Acceptance Model) Volume 8 Nomor 1, 58-62.

Kristanto W., Wahyuningtyas E., Prasetya N.I. (2017). "Penerapan E-Commerce Untuk Penjualan Furniture Pada UD. Tunggal Saudara”. Melek IT. Volume 3 Nomor 1, 29-38.

Pratama F.I., Mustagfirin., Fachreza A. (2020) "Rancang Bangun Aplikasi Presentasi Multi Event Dengan QR-Code Berbasis Restful Web Service” JURTEKSI (Jurnal Teknologi dan Sistem Informasi) Vol. VII No. 1, 15-22. Semarang.

Triharjono, A. (2012). "Sistem Informasi Penjualan Berbasis Website Pada Toko Kencana Ungu Kediri" AMIKOM. Yogyakarta. 